\begin{abstract}
Iranica
Abstracta Iranica Revue bibliographique pour le domaine irano-aryen

Volume 34-35-36 | 2017

Comptes rendus des publications de 2011-2013
\end{abstract}

\title{
Fiona Kidd. The procession scene at Akchakhan-kala
}

\section{Rémy Boucharlat}

\section{(2) OpenEdition}

\section{Journals}

\section{Édition électronique}

URL : http://journals.openedition.org/abstractairanica/42292

DOI : 10.4000/abstractairanica.42292

ISSN : 1961-960X

Éditeur :

CNRS (UMR 7528 Mondes iraniens et indiens), Éditions de l'IFRI

\section{Référence électronique}

Rémy Boucharlat, "Fiona Kidd. The procession scene at Akchakhan-kala », Abstracta Iranica [En ligne], Volume 34-35-36 | 2017, document 31, mis en ligne le 30 juillet 2017, consulté le 26 septembre 2020 URL : http://journals.openedition.org/abstractairanica/42292 ; DOI : https://doi.org/10.4000/ abstractairanica.42292

Ce document a été généré automatiquement le 26 septembre 2020.

Tous droits réservés 


\title{
Fiona Kidd. The procession scene at Akchakhan-kala
}

\author{
Rémy Boucharlat
}

\section{RÉFÉRENCE}

Fiona Kidd. « The procession scene at Akchakhan-kala ». Parthica, 14, 2012 [2013], p. 65-88.

Dans le complexe architectural de Akchakhan-kala dans le delta de l'Amu darya, l'un des plus importants sites de l'ancient Khorezm à la fin du $\mathrm{I}^{\mathrm{er}}$ mill. av.n.è., le corridor occidental du bâtiment quadrangulaire fortifié KY10 porte les restes d'une longue peinture murale. Cette représentation d'une procession est mal conservée et incomplète, mais continuait au-delà de la dizaine de mètres encore visible. Elle montre une alternance de cinq animaux et trois personnages debout. Le thème n'est pas nouveau, comme le montrent Persepolis ou Pazyryk pour l'époque achéménide, ce qui n'exclut pas des éléments hellénistiques ou parthes. Ce serait un argument en faveur de l'interprétation du bâtiment comme centre politique, ce qui est maintenant communément admis, mais plus précisément dans cette peinture murale une représentation d'un culte des ancêtres de l'élite.

\section{AUTEURS}

\section{RÉMY BOUCHARLAT}

UMR 5133 CNRS-Université de Lyon 